\title{
(2) OPEN ACCESS \\ Altria-Juul Labs deal: why did it occur and what does it mean for the US nicotine delivery product market
}

\author{
David T Levy (1) , ${ }^{1}$ David Sweanor, ${ }^{2}$ Luz Maria Sanchez-Romero, ${ }^{3}$ Richard O'Connor, ${ }^{4}$ \\ Maciej Lukasz Goniewicz, ${ }^{5}$ Ron Borland (i) ${ }^{6}$
}

\begin{abstract}
${ }^{1}$ Oncology, Lombardi Comprehensive Cancer Center, Georgetown University, Washington, District of Columbia, USA

${ }^{2}$ Faculty of Law and Faculty of Medicine, University of Ottawa, Ottawa, Ontario, Canada Oncology, Georgetown University, Washington, District of Columbia, USA

${ }^{4}$ Department of Health Behavior, Roswell Park Cancer Institute, Buffalo, New York, USA

${ }^{5}$ Cancer Prevention and Population Sciences, Roswell Park Cancer Institute, Buffalo, New York, USA

${ }^{6}$ School of Psychological

Sciences, University of

Melbourne, Melbourne, Victoria, Australia
\end{abstract}

\section{Correspondence to} Dr David T Levy, Oncology, Lombardi Comprehensive Cancer Center, Georgetown University, Washinton, DC 20007, USA;

d1777@georgetown.edu

Received 29 March 2019 Revised 12 July 2019 Accepted 17 July 2019 Published Online First 4 September 2019

\section{Check for updates}

(c) Author(s) (or their employer(s)) 2020. Re-use permitted under CC BY-NC. No commercial re-use. See rights and permissions. Published by BMJ.

To cite: Levy DT, Sweanor D, Sanchez-Romero LM, et al. Tob Control

2020:29:e171-e174.

\section{INTRODUCTION}

On 19 December 2018, Altria announced an offer of US $\$ 12.8$ billion for a $35 \%$ share of Juul Labs. ${ }^{12}$ The deal combines Altria (formerly Philip Morris), ${ }^{3}$ the company with the largest share of the US cigarette market, with the large and rapidly growing vaping product (aka e-cigarette) company, Juul Labs. ${ }^{45}$ The acquisition price was based on a US $\$ 38$ billion valuation, which was more than twice Juul Labs' August valuation, and a surprise to many investors on Wall Street. ${ }^{1}$ The deal includes a 6-year agreement, in which Altria would not be allowed to acquire additional Juul Labs shares above the agreed 35\%. In addition, Altria dropped its MarkTen e-cigarette brand. $^{2}$

\section{JUUL LABS' MOTIVATIONS FOR THE DEAL WITH ALTRIA}

Juul Labs has clear motivations for the merger. Besides the direct gain to Juul Labs' owners from the acquisition price, ${ }^{1}$ they can also benefit in the legal and regulatory sphere. With its vast experience, Altria can provide Juul Labs support in legal battles regarding patent infringement ${ }^{67}$ and consumer health claims. ${ }^{8}$ With Juul Labs under pressure to respond to Food and Drug Administration (FDA) concerns about youth use of its product,${ }^{10}$ Altria could also help them navigate the regulatory waters.

The deal can also serve to strengthen Juul Labs' future market prospects. The US vaping product industry is still rapidly growing. ${ }^{411}$ Within 5 years, the leading mass-manufactured vaping product in the USA has gone from N-JOY to Blu to Vuse to Juul. ${ }^{4}$ Juul, as the current leader, may be replaced by another technology, product or company. In particular, Juul Labs faces the challenges from competitors producing Juul-like vaping products (eg, BO, Phix and SMOK) ${ }^{12}$ and from open system products that are typically less expensive than Juul. ${ }^{4}$

Altria may directly help Juul Labs to increase sales. Altria has touted how they will help Juul obtain greater access to retail. ${ }^{13}$ While Juul had been in 90000 US retail outlets, Altria's reach extends to 230000 US outlets. In particular, Altria may increase Juul's retail presence through the slotting allowances. ${ }^{14}$ This will not only ensure shelf space but can also provide space near Altria products and retail displays. In addition, Altria has agreed to provide Juul Labs access to its consumers through Juul coupons on its cigarette packs, as well as provide Juul Labs access to its database of more than 10 million smokers. While Juul has been successful attracting youth and young adults, Altria can help attract older smokers.

Financing from Altria can also help protect and maintain Juul's future growth. Altria has historically generated large dividends to stockholders, which technology companies cannot match. While cigarette companies distribute much of their profits as dividends, technology companies need to heavily invest in research and development. Through this deal, Juul Labs is given a large pool of financial resources to develop better products and expand its market. In particular, they may take advantage of Altria's capacity for product testing and development.

\section{ALTRIA'S MOTIVATION FOR THE DEAL WITH JUUL LABS}

While Juul Labs has clear motivations for the deal, Altria's motivations to pay US $\$ 12.8$ billion for a non-controlling stake are less clear. With Juul often used by those attempting to quit cigarette use ${ }^{15}$ and with Altria having a 55\% share of the US cigarette market (mostly Marlboro), ${ }^{3}$ growth in Juul use would likely reduce Altria's profits from cigarette sales. In addition, Altria has recently gained permission from the FDA to market Phillip Morris International (PMI's) heated-tobacco product, iQOS, which is also likely to compete with vaping products for a share of the nicotine delivery market. Thus, increased Juul sales are likely to at least partially reduce Altria's profitability from cigarettes and iQOS.

With the growth of Juul Labs and other vaping firms, ${ }^{5}$ financial markets appear to reflect the major challenges that cigarette companies face from alternative nicotine products. With steeper declines in their sales, Altria and the other two major US cigarette companies, British American Tobacco (BAT) and Imperial, have experienced a steep drop in their stock prices since July $2017,{ }^{16}$ when the FDA announced its plan to encourage the use of safer nicotine delivery products instead of cigarettes. ${ }^{17}$ The per cent reduction in stock prices far exceeds that of general consumer products or for the overall market, and is occurring despite ongoing high profits. ${ }^{1618} 19$

Previous to the growth of the vaping industry, Altria had a lucrative and secure cigarette business model where they could afford complacency and fail to innovate. However, the decline in stock market value as well as their own market intelligence likely showed that disruption from alternative products had hit a tipping point, where they felt compelled to 
act. Altria CEO Howard Willard stated, At a time when e-vapor is going to grow rapidly and likely cannibalize the consumers we have in our core business, if you don't invest in the new areas you potentially put your ability to deliver ....at risk.'2 Indeed, Altria reportedly pursued the Juul Labs acquisition for a year and BAT also reportedly attempted to purchase Juul Labs. ${ }^{2}$

If Altria projected that the rapid growth in Juul use is likely to continue, then obtaining a share of Juul Labs would provide a hedge against losses in cigarette profits as well as earn them a share of the profits from the growing vaping market. In addition, Altria may recoup at least part of its lost cigarette sales by switching its cigarette smokers (eg, Marlboro smokers) to Juul. These gains could be especially great if the FDA were to adopt a nicotine reduction strategy for cigarettes. ${ }^{17}$

The Juul Labs deal may also reflect Altria's corporate culture. As the dominant firm in the US cigarette industry, the investment may help Altria to maintain a semblance of control and their position as leader (as shared with Juul) in the nicotine delivery market. In addition to their relationship to Juul, Altria now controls other products that substitute for cigarettes. Through acquisitions of independent firms, Altria now has a 55\% share of the smokeless tobacco market and a 33\% share of the cigar market, ${ }^{11}$ and have recently acquired a firm producing oral tobacco-derived products. ${ }^{19}$ With all of these products and iQOS and Juul, Altria is able to provide a variety of nicotine products to different consumer tastes, thereby refining marketing efforts to expand sales with stronger market segmentation. As one financial analyst has stated, 'Juul appeals to millennials/hipsters and iQOS appeals to slightly older \& more affluent smokers, ${ }^{19}$ suggesting that Altria is looking at greater market segmentation as the nicotine market is further disrupted.

The deal could also help Altria's reputation by showing that they now embrace harm reduction. As Juul Labs and other companies show that it is possible to make acceptable alternatives to cigarettes, the litigation and regulatory risks of cigarette companies increase as the evidence of them selling an unnecessarily defective and deadly product increases. ${ }^{20}$ Altria could ultimately help their reputation and reduce regulatory and litigation risks by showing that they are actively investing in and seeking to give marketplace advantages to a less harmful product that can replace cigarettes.

In view of the acquisition price, it is likely that Altria views the deal as providing a partial hedge for lost cigarette profits in the face of disruptive technology and vaping as an important part of their future business. Nevertheless, Altria may still gain if the deal leads to a backlash from public health advocates and from legislators and regulators. If the backlash leads to increased scrutiny and regulation of vaping products, Altria can better pursue their main product line, cigarettes, while lessening a major threat to their dominant position in the cigarette market. Indeed, Altria may have been motivated by this potential backlash. Notably, this deal has occurred at the same time as Altria was seeking approval to market PMI's iQOS. With tobacco companies having a relative advantage with heated tobacco products (HTPs), ${ }^{4}$ it may be in their interests to equate the rules for HTPs and vaping products, thereby making both nonviable as competitors to cigarettes, or to favour HTPs over vaping.

\section{THE FUTURE IMPACT OF THE DEAL ON THE US CIGARETTE AND ALTERNATIVE NICOTINE DELIVERY MARKET}

From a public health perspective, the impact of the deal will depend on whether it leads to increased cigarette use (eg, through increased initiation or less cessation) or less cigarette use (eg, as a means of cessation or initiation into e-cigarette or no use rather than cigarettes) than would have occurred in the absence of e-cigarettes. ${ }^{21}$ Independent (ie, non-cigarette) firms have greater incentives than cigarette companies to encourage smokers to switch entirely to vaping, and have played a key role in developing a product that better substitutes for cigarettes. ${ }^{4}$ At the same time, Juul has been associated with increased vaping by youth and young adults. ${ }^{22-24}$ The future public health impact of the Altria-Juul Labs deal is difficult to predict, but will likely depend how the deal affects market competition and future FDA regulation.

The Altria-Juul Labs deal can increase competition in the vaping market by effectively highlighting these vaping products as a lucrative opportunity. By paying such a high price for Juul, the deal signals to other firms the potentially high profits in alternative nicotine products, and can thereby attract product developers, entrepreneurs and venture capitalists. Indeed, if Juul Labs uses this deal to gain current smokers as customers, competitors will see further evidence of the financial benefits.

The deal could also increase competition from other cigarette companies. The Altria-Juul Labs deal appears to be unlike Altria's 2008 purchase of US Tobacco, a US smokeless tobacco company. Altria as well as Reynolds American bought a category of well-established tobacco firms, thereby creating stability and strengthening their cartel-like market structure in cigarettes. ${ }^{25}$ The Juul Labs deal at least in the short-run does not provide Altria the same degree of control as the smokeless tobacco acquisitions. Indeed, the deal may destabilise the rapidly growing vaping market by creating incentives for the other major US cigarette companies, BAT and Imperial, to more strongly market vaping products. Imperial already produces the blu product line, which includes the Juul-like Myblu. BAT markets Vuse e-cigarettes, which had grown rapidly before the entry of Juul, and has already decided to expand their product lines. ${ }^{26}$

At the same time that there are market tendencies that may increase competition, there are consequences that can instead reduce competition. This deal directly removes Altria as an independent competitor in the vaping market by terminating its sales of MarkTen. Before Juul entered the US vaping market, Nielsen data from mass market retail (eg, pharmacies and grocery stores) indicated that Altria had a $16 \%$ share and the four cigarette companies had a $72 \%$ combined share in $2015 .{ }^{4}$ By September 2018, Juul had 72\% of the market (dollar value, $55 \%$ in units sold), while the share of Altria fell to $7 \%$ by July 2018 and combined cigarette firm shares fell to $25 \% .{ }^{4}$ However, mass market retail was estimated to be $40 \%$ of the entire vaping market. Although information is limited on market shares in the vape shop or online consumer channels, cigarette manufacturers have generally not sold their vaping products in these sectors. ${ }^{2728}$ With MarkTen having had a small and declining vaping market share, the impact of their exit from the market is likely to be minimal. However, Altria's potential role as a future competitor is likely more important. After the Juul Labs deal, Altria has less incentive to introduce new vaping products ${ }^{2}$ and to aggressively market PMI's iQOS product. ${ }^{4}$

The deal can also impede competition by Altria working with Juul Labs (eg, through onserts on the outside of packages with coupons for Juul and providing their customer lists for marketing purposes) to insure that those smoking Altria products (eg, Marlboro) switch to Juul rather than other e-cigarette companies' products. To the extent that brand loyalty is created for Juul products, new entrants will face greater barriers to market entry. In addition, Altria is likely to help Juul Labs fight patent infringement cases. 
Besides directly increasing Altria's market share, the deal can generally lead to increased market shares and market power of cigarette companies. At least up until the FDA was given authority over vaping products (the 'deeming rule') in 2016, ${ }^{29}$ market concentration and entry barriers in the vaping market were low, with cigarette companies having relatively small market shares and facing strong competition from independents selling in vape shops and online. ${ }^{4}$ However, as the vaping market becomes more established and the major firms become more entrenched, cigarette companies may be positioned to deter the entry of new firms and products. As previously employed in the cigarette market, they may engage in predatory and discriminatory pricing, limit retail shelf space and expand their product lines to fill market niches. ${ }^{3}$

Through its effects on market competition, the FDA will play a major role in how the Altria-Juul Labs deal affects the vaping market. FDA regulation can have a major impact through its enforcement of the deeming rule, ${ }^{18}$ especially through their impact on the survival of the independent firms. Although new or modified tobacco products will eventually need FDA permission to legally enter the US market, the FDA has not yet been enforcing the requirements that all new e-cigarette products must be approved. ${ }^{30}$ Substantially modified or new brands of e-cigarettes (eg, Juul copycats) have freely entered the market since the deeming rule went into effect. As suggested above, the deal may encourage stricter FDA regulation. Indeed, Altria and Juul Labs will have stronger incentives to encourage stricter regulations, since new offerings will need to secure new product approvals. Cigarette companies, with their previous regulatory experience, are well positioned to overcome regulatory hurdles. Market competition, especially from non-cigarette firms with less regulatory experience and product innovation, would then be reduced.

The Altria-Juul Labs deal has direct implications through its effect on marketing and competition in the vaping market. In particular, the merger could increase the likelihood that independent (non-cigarette-company-affiliated) firms play a lesser role, because of advantages by cigarette companies in eliminating market competition and in meeting requirements of FDA regulation. These tendencies could reduce innovation and increase the prices of vaping products. Thereby, youth vaping may be reduced. At the same, cigarette smoking may be prolonged on a population basis if vaping products become a less viable substitute for cigarettes products.

\section{CONCLUSIONS}

In view of the high price paid by Altria, the deal with Juul shows that Altria now views vaping products as a major threat to its cigarette business. While Altria's yearly profits in cigarettes are under threat, Juul potentially enables Altria to reassert themselves as a major player in the broader market for alternative nicotine products. However, Altria's presence in the US vaping industry as well as the increased presence of other cigarette companies is likely to at least initially increase the role of cigarette manufacturers in the national nicotine product business. In addition to the possibility of increasing prices and reducing innovation of vaping products, particularly with regulatory barriers to new entrants, cigarette companies may use their marketing experience to increase initiation into and reduce cessation from alternative nicotine products. Further, we have confined the analysis to the USA; a full assessment of the impact of the deal will require examining the impact in other countries.
The ultimate impact of the Altria-Juul Labs deal on the nicotine delivery product market is difficult to predict, but will likely depend on Altria's inter-relationship with Juul Labs under the current deal (eg, the extent to which they promote Juul's products in retail settings), future extensions of the deal, the reaction of other current and prospective players and tobacco product regulation. In gauging how this all plays out in the broader nicotine delivery market, better information is needed on the market shares of the different companies through mass market retail, kiosks, online and vape shop consumer channels. The FDA will need to develop a coherent tobacco control strategy, recognising that the demand for non-combustible nicotine delivery products can significantly grow and replace the cigarette market in the coming years. Regardless of one's views on harm reduction, the Altria-Juul Labs deal should serve as a wake-up call on the need to carefully monitor competition in the nicotine delivery market, and evaluate how regulations and policies impact cigarette and non-cigarette firms selling alternative nicotine delivery products.

What this paper adds

- On 19 December 2018, Altria, the company with the largest share of the US cigarette market, announced an offer for a $35 \%$ share of the large and rapidly growing vaping product company, Juul Labs. The implications of this deal have not been discussed in the tobacco control literature.

- The Altria-Juul Labs deal could increase the sales of vaping products through increased promotion of Juul by Altria or through increased competition by the cigarette companies in the vaping product market. However, the deal could also reduce incentives for non-cigarette firms to develop new vaping products, reduce their prices and actively promote their products.

Contributors DTL wrote the original article along with DS, and with advice and comments of all coauthors. Each of the coauthors contributed substantially in the rewriting of the paper.

Funding The authors received funding from the National Cancer Institute under grants P01CA200512 and U54CA229974.

Competing interests MLG also received a research grant and served as an advisory board member to pharmaceutical companies that manufacture smoking cessation medications.

Patient consent for publication Not required.

Provenance and peer review Not commissioned; externally peer reviewed.

Open access This is an open access article distributed in accordance with the Creative Commons Attribution Non Commercial (CC BY-NC 4.0) license, which permits others to distribute, remix, adapt, build upon this work non-commercially, and license their derivative works on different terms, provided the original work is properly cited, appropriate credit is given, any changes made indicated, and the use is non-commercial. See: http://creativecommons.org/licenses/by-nc/4.0/.

\section{ORCID iDs}

David T Levy http://orcid.org/0000-0001-5280-3612

Ron Borland http://orcid.org/0000-0003-0059-178X

\section{REFERENCES}

1 New Altria deal makes Juul Cofounders Billionaires, 2018. Available: https://www. forbes.com/sites/kathleenchaykowski/2018/12/20/new-altria-deal-makes-juulcofounders-billionaires/\#62230a735a67 [Accessed 15 March 2019].

2 Maloney J, Mattioli D. Why Marlboro maker BET on Juul, the Vaping Upstart aiming to kill cigarettes, 2019. Wall St J. Available: https://www.wsj.com/articles/why-marlboromaker-bet-on-juul-the-vaping-upstart-aiming-to-kill-cigarettes-11553313678

3 Levy DT, Chaloupka F, Lindblom EN, et al. The US cigarette industry: an economic and marketing perspective. Tob Regul Sci 2019;5:156-68.

4 Levy DT, Lindblom EN, Sweanor DT, et al. An economic analysis of the Pre-Deeming us market for nicotine Vaping products. Tob Regul Sci 2019;5:169-81. 
5 King BA, Gammon DG, Marynak KL, et al. Electronic cigarette sales in the United States, 2013-2017. JAMA 2018;320:1379-80.

6 PAX Labs, Inc. Granted U.S. patent for nicotine salt e-cigarette, 2015. Available: https://www.prnewswire.com/news-releases/pax-labs-inc-granted-us-patent-fornicotine-salt-e-cigarette-300196459.html [Accessed 15 March 2019].

7 Technology Nicotine Salts E-Lliquid overview, 2018. Available: http://www. vaporclassification.com/reports/NICOTINE_SALTS_E-LIQUID.pdf [Accessed 15 March 2019].

8 North Carolina Sues Juul, setting up a fresh legal fight for the Embattled e-cigarette company. Washington post, 2019. Available: https://www.washingtonpost.com/ health/2019/05/15/north-carolina-sues-juul-setting-up-fresh-legal-fight-embattlede-cigarette-company/?noredirect=on\&utm_term=.f1300b634b31 [Accessed 4 June 2019].

9 E-Cigarette maker JUUL Sued for allegedly targeting young users. Daily business review, 2019. Available: https://www.law.com/dailybusinessreview/2019/04/ 15/e-cigarette-maker-juul-sued-for-allegedly-targeting-young-users/?slreturn= 20190506135937 [Accessed 4 June 2019].

10 CDC blames spike in teen tobacco use on vaping, popularity of Juul, 2019. Available: https://www.cnbc.com/2019/02/11/e-cigarettes-single-handedly-drives-spike-in-teentobacco-use-cdc.html [Accessed 15 March 2019].

11 Well Fargo Securities Equity Research. Nielsen: Tobacco All Channel Data Thru 5/18 Cig Vol Declines Strengthen. New York: Wells Fargo and Company, 2019.

12 Goniewicz ML, Boykan R, Messina CR, et al. High exposure to nicotine among adolescents who use Juul and other vape pod systems ('pods'). Tob Control 2018:tobaccocontrol-2018-054565.

13 Juul now has '800-pound gorilla' to fight FDA, experts warn, 2018. Available: https:// www.nbcnews.com/health/health-news/altria-deal-take-stake-juul-worries-antitobacco-groups-n950536 [Accessed 15 March 2019].

14 Levy DT, Lindblom EN, Fleischer NL, et al. Public health effects of restricting retail tobacco product displays and ads. Tob Regul Sci 2015;1:61-75.

15 Patel M, Cuccia A, Willett J, et al. JUUL use and reasons for initiation among adult tobacco users. Tob Control 2019;28:681-4.

16 Credit Suisse GER. Global tobacco High-single-digit EPS growth at risk. London: Credit Suisse Securities, 2018.

17 Gottlieb S, Zeller M. A Nicotine-Focused framework for public health. N Engl J Med 2017;377:1111-4
18 Citi Research Equities. Altria, Juul Purchase Signals MO's Lack of Confidence in Cigarettes. Australia: Citgroup, Ltd, 2018.

19 Wells Fargo Securities Equity Research. MO: Continues Its Aggressive Pivot \& We're On Board! - MO Acquires 80\% Stake in Oral Nicotine Product on! New York: Wells Fargo and Company, 2019.

20 Liberman J, Clough J. Corporations that kill: the criminal liability of tobacco manufacturers. Crim Law J 2002;26:1-12.

21 Levy DT, Cummings KM, Villanti AC, et al. A framework for evaluating the public health impact of e-cigarettes and other vaporized nicotine products. Addiction 2017; 112:8-17.

22 Hammond D, Wackowski OA, Reid JL, et al. Use of JUUL e-cigarettes among youth in the United States. Nicotine Tob Res 2018;66.

23 McKeganey N, Russell C. Prevalence of awareness and use of JUUL e-cigarettes in a national probability sample of adolescents in the United States. Am J Health Behav 2019;43:591-605.

24 Vallone DM, Bennett $\mathrm{M}$, Xiao $\mathrm{H}$, et al. Prevalence and correlates of JUUL use among a national sample of youth and young adults. Tob Control 2019;28:603-9.

25 Levy DT, Yuan Z, Li Y. The US SimSmoke tobacco control policy model of smokeless tobacco and cigarette use. BMC Public Health 2018;18:696.

26 Wells Fargo Securities Equity Research. BAT's capital markets day Takeaways, bat throws down the Gauntlet on JUUL. New York: Wells Fargo and Company, 2019.

27 Kamerow D. The battle between big tobacco and vape shops. BMJ 2014;349:g5810.

28 Sussman S, Baezconde-Garbanati L, Garcia R, et al. Commentary: forces that drive the Vape shop industry and implications for the health professions. Eval Health Prof 2016;39:379-88

29 Deeming tobacco products to be subject to the federal food, drug, and cosmetic act, as amended by the family smoking prevention and tobacco control act; regulations on the sale and distribution of tobacco products and required warning statements for tobacco products, 2016. Available: https://www.federalregister.gov/ documents/2016/05/10/2016-10685/deeming-tobacco-products-to-be-subject-tothe-federal-food-drug-and-cosmetic-act-as-amended-by-the [Accessed 15 March 2019].

30 Modifications to compliance policy for certain deemed tobacco products, 2019. Available: https://www.fda.gov/downloads/TobaccoProducts/Labeling/RulesRegulat ionsGuidance/UCM633281.pdf [Accessed 15 March 2019]. 